\title{
Research on the Role Reconstruction of Teachers in the Intelligent Era under the Framework of 5C Core Literacy Model: On the Construction of Teachers' Teaching Ability in Open University
}

\author{
Yanfang Yu, Yuan Chen \\ Zhejiang Radio and TV University (Zhejiang Open University), Hangzhou, China \\ Email: chy0501@126.com
}

How to cite this paper: Yu, Y.F. and Chen, Y. (2020) Research on the Role Reconstruction of Teachers in the Intelligent Era under the Framework of 5C Core Literacy Model: On the Construction of Teachers' Teaching Ability in Open University. Open Access Library Journal, 7: e6916.

https://doi.org/10.4236/oalib.1106916

Received: October 21, 2020

Accepted: December 19, 2020

Published: December 22, 2020

Copyright $\odot 2020$ by author(s) and Open Access Library Inc.

This work is licensed under the Creative Commons Attribution International License (CC BY 4.0).

http://creativecommons.org/licenses/by/4.0/

\begin{abstract}
With the advent of the intelligent era, the changes brought about by technology are affecting and changing everyone's work and life. The comprehensive reform in the economic field and the reconstruction of governance mode in the social field make education have to keep pace with the pace. The structure of education ecosystem is also changing constantly. The relocation of teachers' role is becoming the most important one in the system changes. Therefore, the role of teachers in Open University is repositioned. Teachers of development university are a special group. They are faced with the educational reform under the guidance of core literacy and the application of the latest educational technology. This paper tries to focus on the two factors of core literacy and artificial intelligence education, through interviews and research, on the basis of absorbing the role positioning of traditional teachers, combined with the characteristics of Open University, puts forward suggestions on the role positioning and teaching ability requirements of open university teachers.
\end{abstract}

\section{Subject Areas \\ Education \\ Keywords \\ Core Literacy, 5C Model, Role Reconstruction, Open University, Capacity Building}

\section{Introduction}

In recent years, with the development of artificial intelligence related technology, 
great changes have taken place in the society, which will also bring changes in education. Especially since UNESCO launched the education 2030 framework for action in 2015, great changes have taken place in global education, and countries around the world have launched their own core literacy training programs. From basic education to higher education, the cultivation of thinking ability is the ultimate goal of education, which also leads to changes in educational organization, learning space, learning content, learning methods, educational objectives and evaluation system. Among them, the problem of teacher's role orientation and reconstruction in education has attracted more and more global attention.

Finland's "seven core literacy" and its interdisciplinary integrated teaching method for core literacy training and implementation, students need to learn in the process of solving practical problems, and teachers are no longer just imparting knowledge in books. As a pioneer of university reform, the University of Minerva in the United States has reconstructed the teaching contents and teaching methods of the whole four-year undergraduate course, and will cultivate "have" Effective communication, effective cooperation, innovative ability and critical thinking are directly integrated into the education of basic courses. As the bottom thinking ability to open up all disciplines, the traditional role and status of teachers and students have been completely subverted in the whole four-year undergraduate learning process, and the boundary between teachers and students is gradually blurred. In China, the role of teachers in Beijing Moon Exploration university has been clearly defined as learning Experience designer [1].

In all kinds of schools at all levels, open university teachers are a relatively special and representative group. At present, there are more and more researches on the role transformation of open university teachers around the core literacy, but most of them are on the empirical level. Facing the continuous development of information technology and the rapid change of global education, the research on the change of Open University Teachers' role needs to be carried out. It is necessary to keep pace with the times, absorb the characteristics of teaching and learning in the intelligent era, put forward new practical methods, reposition their own role requirements, and construct their own teaching ability construction system.

This paper will start from the global education reform of pursuing core literacy, demonstrate why it is necessary to construct the reasons for the change of teachers' role from the perspective of core literacy and the educational characteristics of intelligent era. Combined with the characteristics of open education, this paper gives suggestions on the role orientation and teaching ability requirements of teachers in Open University.

\section{Core Literacy Has Become the Consensus of Global Education Reform}

\subsection{Global Educational Change}

At present, there are four major changes in global education: first, the continuous change of global education evaluation. Pisa test two rounds of results re- 
leased (20152018) caused a lot of controversy. The focus of controversy is whether the three test items can be carried out around the changes of social needs to test students' future oriented core literacy. To this end, the official testing agency is constantly developing and iterating new projects, and has released the learning compass 2030 (2019), which plans to test students' self navigation ability in unfamiliar environments in a more innovative way in the future. The continuous improvement of Pisa test proves that students' learning motivation, whether they know the meaning of learning and what core qualities they have are more important in the future than taking knowledge and getting high marks.

Second, the curriculum reform from Finland. In 2019, many Finnish secondary schools have added a series of content to solve real problems. All new courses are completed through a series of specific and challenging interdisciplinary learning tasks, known as "Phenomenon-Based learning". The main feature of this kind of teaching design is to move the learning scene to the real world, and cultivate students' comprehensive problem-solving ability, not just how much knowledge they have mastered and memorized. Third, the change of teachers' role. With the emphasis on core literacy in global education, the role of teachers is also being reconstructed.

The role of a teacher has changed from a single role of preaching, teaching, and resolving doubts to multiple roles: in the project-based learning of students, he is a growth coach; in the course of career planning, he is a consultant; in the sharing of teaching and research among colleagues, he has become the leader of the group; in the skill competition, the teacher can be a judge or a participant. The traditional boundary between teachers and students is gradually blurred, which means that the nature of teachers' work has changed greatly. Fourth, project-based learning has become an important means of core literacy training. The "wise Education Award 2019 was awarded to Larry Rosen stock, founder of high tech high school in the United States.

The reason is that he has spent 19 years exploring PBL project-based learning with "no unified teaching materials and no standardized examination", and installed learning engine for more than 5000 students. Therefore, we need to redefine what to learn and how to learn. On this issue, the representative teaching in the world includes flipped classroom, stem learning, project-based learning and game learning in the United States, phenomenon based learning in Finland, studio learning in the UK, less teaching and more learning in Singapore, etc.

Although these methods look dazzling, they all have a common feature, which is from passive learning for standard answers to active learning for forming solutions. The most important one is the implementation of core literacy training. At present, task-based learning and interdisciplinary project-based learning are the two most concerned teaching models. The success of project-based learning design is directly related to the cultivation and implementation of core literacy.

\subsection{C Core Literacy Model}

After making clear what to learn and how to learn, the next step is the change of 
educational objectives. The United States was the first to start to reshape educational goals. The $21^{\text {st }}$ century learning alliance is an organization jointly initiated by the world's leading enterprises, universities and non-governmental organizations. It was established in Washington, D.C. in 2001. After years of research, the organization jointly launched the $21^{\text {st }}$ century learning framework, which focuses on four areas: life and professional literacy; learning and innovation literacy; information, media and technology literacy; and key disciplines and $21^{\text {st }}$ century themes. The core of the framework is learning and innovation literacy, the most important of which is the $4 \mathrm{C}$ literacy model, namely cooperation, communication, critical thinking and innovation. These qualities are mainly cultivated through subject learning and interdisciplinary theme learning.

This framework has become the basic reference for many countries to set educational goals. On the basis of this framework, countries have launched their own skills and learning framework for the $21^{\text {st }}$ century. In 2010, Singapore put forward the $21^{\text {st }}$ century skills of Singapore students, including three aspects: first, communication, cooperation and information skills; second, civic literacy, global awareness and cross-cultural communication skills; third, critical and innovative thinking.

Global change took place in 2015. Just after the end of the first 15 year education plan of the new century, UNESCO launched the education 2030 action framework, which for the first time proposed that "Global Literacy" must become an important dimension for countries to formulate literacy frameworks. Since then, more than 70 countries have responded positively and launched their own 2030 plans.

With the deepening of curriculum reform of basic education in China, core literacy education has been taking root and developing rapidly in China, and has achieved rich research and practical results. Beijing Normal University cooperates with the $21^{\text {st }}$ century learning alliance of the United States. On the basis of 4C model (critical thinking, innovation, communication and cooperation) of 21 st century core literacy proposed by Beijing Normal University, cultural understanding and inheritance literacy are added to form 5C model.

The model includes five first level dimensions and 16 second level dimensions: cultural understanding and inheritance literacy (including cultural understanding, cultural identity and cultural practice); critical thinking (including questioning and criticizing, analysis and demonstration, comprehensive generation, reflection and evaluation); innovation literacy (including innovative personality, innovative thinking and innovative practice); communication literacy (including empathy, deep understanding, and effective form) Cooperation literacy (including vision identification, responsibility sharing, consultation and progress) [2]. To implement the core literacy into the classroom, the current common practice is to sink it to the core literacy of the discipline. For example, the "new curriculum standards for senior high school" issued by the Ministry of education in 2018 cond. 


\subsection{The Change of Teacher's Role Orientation at Home and Abroad}

With the implementation of the core literacy education model, the traditional way of "one textbook dominating the world" is no longer in use. In order to support students' active learning, in addition to regular teaching, teachers should change their roles in different roles, such as guider, growth coach, and learning club leader. As a teacher, he should also know how to design emotional experience, guide students' learning and feedback learning Process and evaluate learning outcomes. It is said that many jobs in the intelligent era will be replaced by machines. Obviously, this role change of teachers is doomed to be irreplaceable [3]. From the perspective of China, there have been obvious changes in the role of teachers in many schools. As a model of reconstructing the role of teachers in China, Beijing Moon Exploration university has positioned teachers' roles in this way. Teachers are designers of learning experience, learning mentors, evidence-based practitioners and lifelong learners.

From the perspective of foreign countries, educators have been replaced by teachers in the International Society for Technology in Education 2017. ISTE is a non-profit professional organization with global membership and dominant position in the field of educational science and technology. It is committed to promoting the rational use of information technology, supporting and improving K-12 education and teaching, science and technology and management. The change of ISTE reflects the change of teacher's role, that is, from a teacher or teacher who imparts knowledge in teaching activities to an educator who promotes the development of students, teachers themselves and colleagues.

The roles of teachers in the national standards for educational technology for educators (2017) in the United States can be divided into roles at the level of enabling professional development, such as learners, leaders and citizens, and the roles of promoting students' development, such as collaborators, designers, promoters and analysts, as shown in Table 1 . The specific requirements for various roles are as follows.

Table 1. Changes in dimensions of teachers' roles in the fifth edition of ISTE national standards for Teacher Education Technology.

\begin{tabular}{|c|c|c|c|c|}
\hline 1993 edition & 1997 edition & 2000 edition & 2008 edition & 2017 edition \\
\hline $\begin{array}{l}\text { Dimensionless } \\
\text { Division }\end{array}$ & $\begin{array}{l}\text { 1. Basic operation and } \\
\text { concept of computer } \\
\text { 2. The individual and } \\
\text { professional practice of } \\
\text { Technology } \\
\text { 3. Application of } \\
\text { technology in Teaching }\end{array}$ & $\begin{array}{l}\text { 1. Technical operation and concept } \\
\text { 2. Design learning environment and } \\
\text { experience } \\
\text { 3. Teaching, learning and Curriculum } \\
\text { 4. Evaluation and evaluation } \\
\text { 5. Work efficiency and professional } \\
\text { practice } \\
\text { 6. Social and ethnic laws and issues of } \\
\text { social and ethnic minorities }\end{array}$ & $\begin{array}{l}\text { 1. Promote and motivate the learning and } \\
\text { creativity of Science } \\
\text { 2. Learning and evaluation of design and } \\
\text { development in digital age } \\
\text { 3. Become a model of work and learning in the } \\
\text { digital age } \\
\text { 4. Enhance citizen awareness and sense of } \\
\text { responsibility in the digital age, and become } \\
\text { a model } \\
\text { 5. Focus on professional growth and leadership }\end{array}$ & $\begin{array}{l}\text { 1. learner } \\
\text { 2. leader } \\
\text { 3. citizen } \\
\text { 4. collaborators } \\
\text { 5. designer } \\
\text { 6. Promoters } \\
\text { 7. Analyst }\end{array}$ \\
\hline
\end{tabular}




\subsubsection{Learner}

At the level of learners, first of all, educators should explore the effective practice of using technology to improve students' learning ability, and improve their own teaching through mutual learning and cooperation. Secondly, educators should set professional learning objectives, explore the teaching method supported by information technology, use this teaching method, and reflect on its effectiveness. Third, through the establishment and active participation in regional and even global learning network, to pursue their own interest in professional development. Keep an eye on the achievements of students to improve their learning effect and keep pace with the latest research findings in the field of learning science.

\subsubsection{Leader}

As a leader, first of all, educators should seek and grasp the opportunity to become a leader, provide strong support for students' ability acquisition and academic success, and promote teaching and learning. Secondly, educators should promote and accelerate the formation of a vision of shared technology learning through contact with educational stakeholders. Thirdly, educators should advocate that students have fair access to educational technology, digital resources and learning opportunities in order to meet the diversified and personalized needs of students. Fourth, to set an example for colleagues in the identification, research, management and application of new digital resources and tools.

\subsubsection{Citizen}

As a good citizen, educators should first help learners form positive, responsible and communicative experiences, and show empathy on the Internet, so as to establish interpersonal relationships and communities on the Internet. Secondly, educators need to build a learning culture to enhance students' thirst for knowledge, cultivate their critical analysis ability for network resources, and promote students' digital and media literacy. Third, we should guide students how to use information tools to protect personal intellectual property and property safely, reasonably and legally. Fourth, we need to demonstrate and recommend the management of personal data and digital identity to protect the privacy of students' data.

\subsubsection{Collaborator}

Educators are committed to working with colleagues and students to identify problems, share resources, and exchange ideas to improve practice and solve problems.

\subsubsection{Designer}

As the designer, first of all, educators should be able to identify and adapt to the changes of learners, and design activities and environments driven by learners and close to the real world. Secondly, educators should create personalized learning experience through technology in order to adapt to learners' differences and 
different needs, so as to promote learners' autonomous learning. Thirdly, in order to achieve the maximum depth of learning, digital tools and resources can be used to design learning activities consistent with the content standards. Fourth, in order to participate in and support the learning of learners, research and apply the principles of instructional design to create a new digital learning environment.

\subsubsection{Promoters}

As a promoter, first of all, educators should use technical means to support students' learning in order to meet the ISTE learner standard. Secondly, educators should cultivate a culture to enable students to achieve learning goals and achieve learning outcomes in autonomous learning and group learning. Thirdly, educators should manage the use of technology and students' learning strategies in the fields of digital platform, virtual environment and practice space. Fourth, create opportunities for students to use design programs and computer thinking to innovate and solve problems, and cultivate students' sense of challenge. Fifth, in order to communicate ideas and knowledge, strengthen the relationship between people, focus on shaping and cultivating students' creativity and creative expression.

\subsubsection{Analyst}

As analysts, educators should understand and use data-driven teaching to support students to achieve learning goals. Including: first, to provide students with a variety of different learning methods, to show students' ability, and to reflect on their use of technology in learning. Second, the use of technology to design and implement a variety of formative assessment and summative evaluation, in order to meet the needs of learners, and provide timely feedback and guidance for students. Thirdly, the evaluation data are used to guide the teaching process, and actively communicate with students, parents and other stakeholders in order to realize students' self-guidance.

\section{Educational Characteristics and Educational Reform in the Era of Intelligence}

\subsection{Educational Characteristics in the Intelligent Age}

The education in the intelligent age must be inseparable from the education of artificial intelligence. The artificial intelligence education here contains two meanings, one is the application of artificial intelligence technology in education, the other is the education of thinking ability and artificial intelligence technology knowledge in the intelligent era [4].

The application of artificial intelligence technology in the field of education means the challenge and subversion of the traditional education mode: first of all, artificial intelligence technology not only changes the educational goal of traditional education, but also breaks through the traditional education mode. The goal of education has also changed globally. From the traditional exam oriented 
education to cultivate students' core literacy education, from a single book knowledge to thinking transmission. Through artificial intelligence, we can observe and analyze students' learning patterns and individual differences, and break through the stereotyped teaching methods of past contents and modes. A large number of data prove that under this mode, students' academic performance has been improved. Compared with the students under the traditional education mode, the students' academic performance has been improved in terms of course completion time, course passing rate and examination results.

At the same time, artificial intelligence education also makes universal quality education possible. While improving the efficiency of examination oriented education, it injects elements such as speculative training and innovation ability training to cultivate students' ability in an all-round way. Secondly, from the perspective of education mode, intelligent adaptive learning provides personalized solutions to the specific situation and individual needs of students; AI, as the main teacher, has changed the whole teaching process, freeing teachers from the large amount of inefficient work that they used to spend on correcting assignments and papers and daily management, so as to focus on creative learning research and students' pairing Communication creates time and opportunity. AI aided decision-making is based on big data generated by teaching activities to help teachers better grasp the teaching situation. AI breaks the barriers to the flow of information and resources.

The emergence and Realization of the concept of smart campus promote the Internet connection of hardware facilities in the campus, accelerate the decisionmaking of the campus according to the data, realize the accurate teaching, and further improve the learning speed and flexibility; artificial intelligence realizes the information circulation and cross regional resource exchange within the campus, which breaks through the barriers of information and resource circulation. In general, AI education creates the value of traditional education from three aspects: teaching quality, teaching efficiency and teaching equity, which is of great significance to students, teachers, schools and regional education systems.

With the development of intelligent education platform, many of teachers' previous work will be replaced by artificial intelligence, and the general "test, practice, learning and teaching" can be applied intelligently. Continuous intelligent adaptation and other algorithm system applications, students complete closedloop learning. Intelligent adaptive learning system can collect students' learning behavior data, plan the optimal learning path of students according to their current ability, and automatically push online teaching videos and other learning content to complete the closed-loop learning process. It can record students' learning behavior data in real time through continuous intelligent adaptation, and recommend teaching videos of corresponding knowledge points through test and practice. It applies the system of personalized recommendation, big data analysis and collection, and can apply the algorithm technology to all teaching links. Let teachers spare more time to carry out more valuable teaching work. Figure 1 
shows the architecture of general intelligent adaptive teaching platform.

\subsection{Artificial Intelligence Changes Education Industry}

\subsubsection{Intelligent Technology Redefines Education Ecosystem}

Although the application of artificial intelligence technology is still in its infancy, the problems in new fields of all walks of life are different, but the effective application of big data is a common method to solve various problems in different fields. The application of artificial intelligence in the education industry is also the same. Through data-driven continuous innovation of the education industry ecosystem, education has ushered in a wave of intelligent change. Figure 2 shows the trend of intelligent education in China. (source: global education intelligence development report in 2019).

\subsubsection{The Role Reconstruction of Education Industry Ecosystem Brought by Artificial Intelligence}

Artificial intelligence will reconstruct the ecology of education industry, and provide users with artificial intelligence education content, tools and related services based on artificial intelligence technology. Through receiving user data, analyzing and feedback, it can be applied to the five links of "teaching, learning, evaluation, testing and practice" in the learning process to produce personalized

\section{Students / educational objects}

\begin{tabular}{|l|l|l|}
\hline Education content & Educational tools & Education services \\
\hline Knowledge domain module & Teaching module & Teaching module \\
\hline $\begin{array}{l}\text { Learning content } \\
\text { rule } \\
\text { Problem knowledge domain module }\end{array}$ & $\begin{array}{l}\text { Tearning plan } \\
\text { diagnosis } \\
\text { supervise } \\
\text { Learning content recommendation } \\
\text { Learning behavion }\end{array}$ & $\begin{array}{l}\text { personal information } \\
\text { test Learning Journal }\end{array}$ \\
\hline
\end{tabular}

Education platform

Personalized recommendation engine: personalized learning path and learning content recommendation

Big data analysis system: analysis and processing of learning data

Big data acquisition system: real time collection of behavior data of each student

Figure 1. Intelligent adaptive teaching platform. 
Artificial intelligence technology is indispensable The integrated development of science and technology and education mainly relies on artificial intelligence technology to continuously understand and close to the personalized needs of users

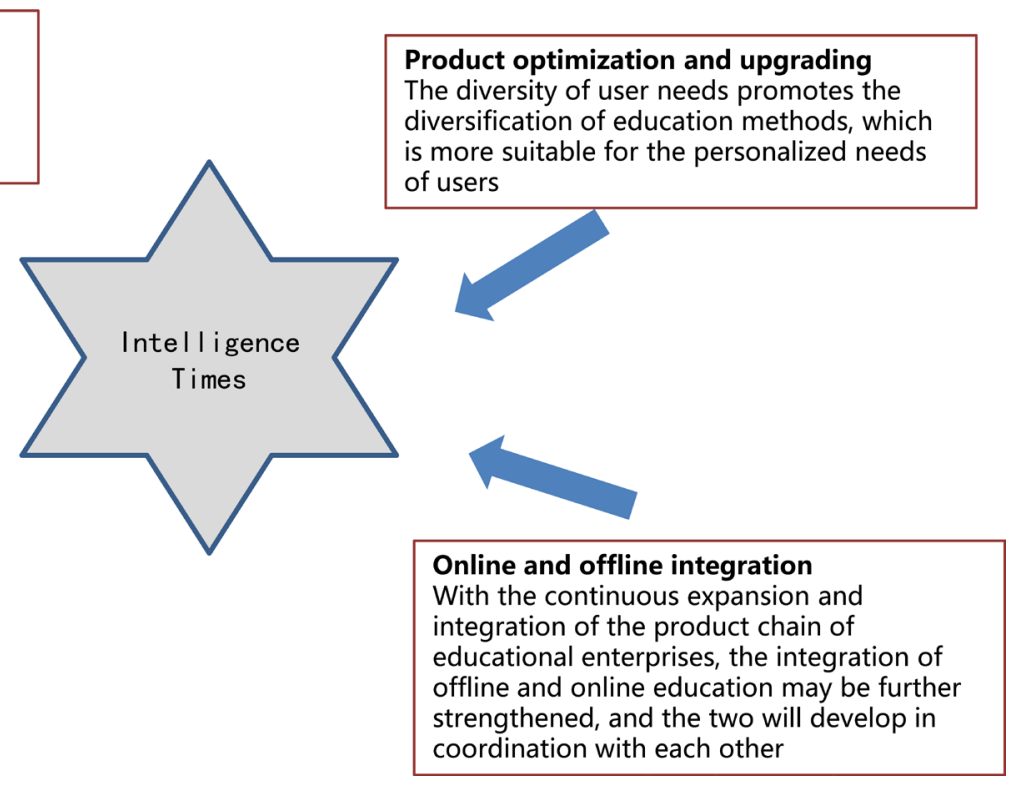

Figure 2. Trend of intelligent education in China.

solutions and effective feedback for learners. This will reconstruct the relationship between the participants in the education industry ecosystem, improve students' learning efficiency, and redefine the education industry [5].

Intellectualization promotes the change of roles and responsibilities of participants in education ecosystem. The traditional education is mainly carried out in the form of class system and face-to-face interaction between teachers and students. With the in-depth development of the trend of intelligent education, the traditional form of education began to intelligent transformation, online teaching, intelligent adaptive education and other emerging means began to become popular. This determines that the role and responsibility of the participants in the AI education ecosystem may change. At the same time, with the continuous influx of new members in the education circle, this change will be more obvious. At present, the participants of AI education ecosystem mainly include users, education training support institutions and AI education enterprises, as shown in Figure 3.

Among them, the users here mainly refer to the users of intelligent education promoting educational products, including not only the most terminal students in the traditional sense, but also the users of institutions such as curriculum guidance centers and schools as the focus of development in the next stage. Support institutions refer to AI technology promoters, including government and non-governmental education support institutions. Their responsibilities are also changing. They pay more attention to the construction of smart campus and focus on promoting the upgrading of campus hardware facilities and technology. Through education funds, the government supports schools to build information management teaching system, build official platform, and promote future teachers' man-machine cooperation project to promote campus intelligence. 


\section{Artificial intelligence education enterprise}

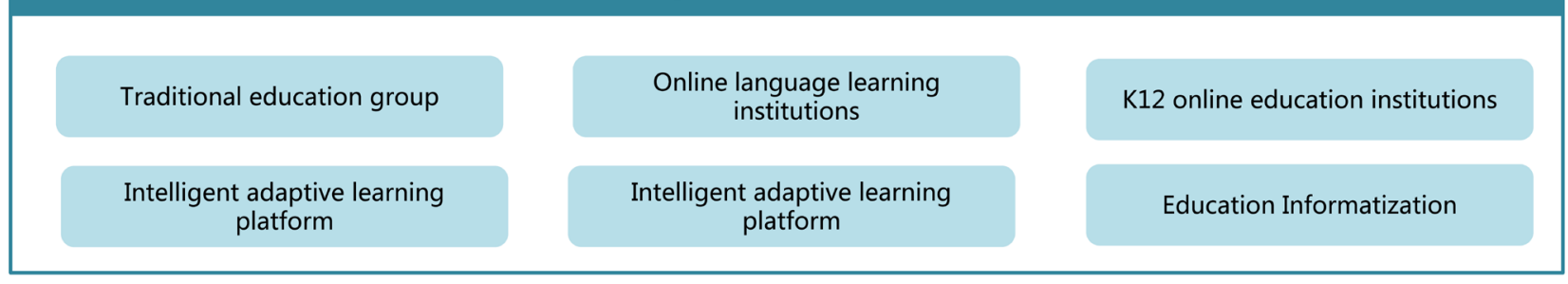

\section{Supporting agencies}

\section{Supporting agencies}

\section{NGOs}

\section{user}

To $\mathrm{B}$

\section{Schools / off campus} training institutions
To $\mathrm{C}$

\section{Students / employees}

Figure 3. Education ecosystem of artificial intelligence.

For example, Shanghai, through the construction of big data platform for education, uses data warehouse, data mining and big data analysis to make deep use of educational data, thus providing support for educational management decision-making and process optimization. NGOs participate in the process of supporting through government policies, such as "Shanghai micro school" to build a platform for the collection of educational learning resources by aggregating internet education providers. The team of AI education enterprises is also expanding, and more technology start-ups have begun to join the ecological circle. It includes a comprehensive education group represented by New Oriental and good future. The joining of such enterprises will help to further improve the overall layout of AI education and build a more perfect ecological circle.

\section{The Characteristics of Open University and Its Requirements for Teachers' Teaching Ability}

\subsection{The Characteristics of Open University and Its New Requirements for Teachers}

Teaching ability is the core element in the structure of teachers' ability and the concentrated embodiment of many qualities of teachers. Open University is a new type of university which is different from ordinary universities. In the process of continuous reform and transformation, the composition of teaching ability elements and possible development approaches of open university teachers are 
bound to present the characteristics of diversity and complexity. In the critical period of the transformation and construction of Open University, teachers are also faced with challenges such as role change, new ideas, new models, new technologies and so on. How to improve the teaching ability of Open University Teachers in line with the characteristics of the times, open university characteristics, social and personal development needs is an important issue to be explored.

Open University is a new type of Open University supported by modern information technology, which provides continuing education and non diploma education to all members of the society and serves lifelong learning. The orientation of "new university" requires teachers of Open University to play a special role in the construction of learning society and lifelong learning system [6]. In the face of new school running mode and teaching methods, as well as information technology innovation and diversified learning needs of learners, teachers' teaching ability of open university should be constantly updated and improved.

\subsection{The Role Orientation and Teaching Ability Requirements of Teachers in Open University}

\subsubsection{Open up the Role of Teachers}

According to the connotation of Open University, we can draw that the teacher of Open University needs to have multiple open thinking ability, the ability to communicate with all kinds of students at different levels, the ability to effectively cooperate with inside and outside the system, and a good sense of service. In particular, they should have a strong ability of information-based teaching and resource construction, which requires teachers to have the ability of information-based teaching and resource construction Ability of continuous learning. If these abilities are defined by different roles, they can be corresponding to the roles of mentor, growth coach, leader of learning community, lifelong learner, etc.

When teachers are faced with multiple roles, the nature and mode of work must be changed. Otherwise, the workload will hinder the transformation process. How to change it? We need to take advantage of the advantages of various technology applications in the intelligent era. According to the characteristics of online and connected in the intelligent era, we can fully connect various resources to help us complete those alternative things, including tutors in off campus institutions, which can realize artificial intelligence technologies such as face recognition, academic quality tracking and test paper analysis, and also connect industry experts, product designers and technical R \& D personnel on the working site to obtain the latest technology Application, understanding the frontier of science and technology. These are the greatest values of teachers in the era of intelligence.

\subsubsection{How to Improve Teaching Ability of Open University Teachers}

According to the current orientation of Open University and some characteris- 
tics of intelligent era, we think that the ability of course teaching design, teaching organization and management and learning resources construction should be the most basic and important teaching ability construction content of open university teachers.

\section{1) Ability of course teaching design}

Based on the characteristics of Open University, teachers should study the teaching characteristics of Open University when designing teaching. First of all, the traditional classroom teaching focuses more on thinking and organizing teaching from the perspective of "teaching". Open University Distance Open Education, more from the perspective of learners to carry out teaching design. It is necessary to organize and implement the teaching process from the perspective of "learning" from the perspective of students' needs and personality characteristics. This paper makes a comprehensive analysis and Research on the elements in the teaching process, grasps the relationship between them as a whole, scientifically integrates the learning resources, learning tools and means of various media, and applies them in a targeted way. On the basis of understanding the teaching characteristics of Open University, we should establish teaching objectives.

According to the teaching materials and related learning resources, teaching objectives should be designed in accordance with students' knowledge and ability. The learning contents and teaching activities should be carried out around the teaching objectives. Secondly, we should organize the teaching content according to the situation of the learning object, choose the teaching strategy, and establish the feedback and evaluation system.

\section{2) Capacity building of learning resources}

Learning resources are an important factor that affects the effective development of open and distance education. The teaching mode of Open University is mainly online, and the mode of combination of online and offline is implemented. Therefore, learning resources become the main carrier of knowledge and the media of teachers and students. There are many types of open universities, including continuing education, non academic training, community education, and education for the elderly. The requirements for learning resources are also different, and the resources construction ability of teachers is different from that of ordinary universities.

The capacity of resource construction includes the capacity of resource production and resource integration. The ability of resource production is mainly the ability of systematic teaching design which shows the teaching content with resources as media. Resource production needs the cooperation of teachers and technicians. Therefore, the ability of resource production not only requires the mastery of the curriculum, the understanding of students and the presentation design of teaching content, but also has higher requirements for teachers' communication ability. Resource integration is to optimize the combination of all kinds of resources according to teaching tasks and objectives, so as to realize the 
effective utilization of resources. At present, there are a lot of high-quality resources in all kinds of platforms in the world, and the open university system itself also has a large number of ready-made network teaching resources. It is an effective way to eliminate the existing network teaching resources.

\section{3) Teaching organization and management ability}

The ability of teaching organization and management is the ability of teachers to regulate and control various elements in teaching, so that teaching can be carried out smoothly.

First of all, we should integrate the teacher resources in the system. The open university is a system of running a school. Only when the goal of teachers' growth is consistent with the strategic goal of the whole open university system can the overall strength of the system be brought into full play. This requires the establishment of an effective information communication mechanism, the cultivation of subject leaders, and the effective integration of system teacher resources. Clear the tasks of provincial teachers in different levels of the system, build an effective communication platform, and realize the exchange of information between teachers and curriculum teaching discussion. Second, we should have a complete teaching program. This program mainly includes syllabus, assessment requirements, teaching implementation rules and so on. Third, we should do a good job in guiding learning and teaching. The diversification of learning methods leads to the change of teaching methods. Teaching guidance is an important work of Open University. We can use blog, learning space, teaching platform, nailing, we chat or QQ group and other means to do a good job in teaching, and carry out various forms of teaching and scientific research activities.

Fourth, we should improve the mechanism of supervision, feedback and evaluation. Open education is mainly based on distance education, which has a great degree of learning freedom. Students are also easy to lose their learning direction, or have a sense of loneliness, which affects their learning enthusiasm. Teachers should guide and supervise students' learning process, and timely evaluate and revise the learning effect.

\subsection{Suggestions on Improving the Teaching Ability of Teachers in Open University}

Based on the general theory construction of Open University Teachers' teaching ability construction, we believe that the key to improve teachers' teaching ability is to guide teachers to attach importance to teaching and curriculum construction, improve the training mechanism, and build a growth platform. First of all, establish and improve the scientific evaluation mechanism. The establishment of the evaluation mechanism should be based on the elements and characteristics of teaching ability of teachers in Open University, and the evaluation standards of teaching ability of expert teachers, backbone teachers and famous teachers should be constructed, with emphasis on the academic level of teaching. In order to fully reflect the real level and influence of teachers, we should increase the 
weight of teaching ability in the promotion of professional titles, and ensure that the evaluation system plays a positive role in the development of teachers' teaching ability.

Secondly, it is necessary to establish an effective assessment mechanism. We should pay attention to the analysis and Research on the characteristics of teachers' posts in open and distance education. On this basis, we should formulate the teacher assessment mechanism. We should not only pursue the number of teaching and scientific research achievements, but also let teachers devote themselves to teaching and educating people, not impetuous, step by step, and have the courage to innovate, so as to improve their teaching ability by stimulating their internal interest in education and teaching.

\section{Summary}

Education expert Shen Zuyun pointed out in the global education report that the change of education law usually includes seven key factors: organization, space, educator, learning content, learning method, education goal and evaluation system. These seven factors have been running through the process of education development. Li Kaifu said that "talking about education cannot be separated from the great economic and social transformation". Looking back on history, we can find that in different stages of economic and social transformation, education pays different attention to these seven factors and changes. In today's intelligent era, attention to teachers, especially to teachers' role in education, has never happened before some changes.

This change not only subverts the traditional role of "preaching, imparting knowledge and solving doubts" caused by the characteristics of social development in the intelligent era, but also is inseparable from the requirements of the current global education reform for the reconstruction of teachers' roles. Especially during the epidemic period, teachers' role transformation and teaching ability requirements have been unprecedented challenges. Before the epidemic, the plight of school teachers was mainly teachers' teaching for middle school and teachers. Students' high-level thinking and ability training were insufficient, the interaction between teachers and students was limited, and teaching evaluation could not be comprehensive and accurate. Since the epidemic, the problems faced by teachers were even more unprepared. Role transformation and online teaching ability improvement have become the biggest problems at present. Open universities are more affected by the development of information technology. It is not only the demand of education and social development, but also the responsibility of every teacher in this era.

\section{Project Source}

Development and implementation of project-based learning curriculum based on core literacy cultivation (Project No.: xjg 202001), The general scientific research project of Zhejiang Provincial Department of education in 2019 "looking 
at the integration paradigm of interdisciplinary curriculum from the perspective of Postmodern Education (Project No.: 201941710).

\section{Conflicts of Interest}

The authors declare no conflicts of interest regarding the publication of this paper.

\section{References}

[1] Jiang, G.J. (2020) Research on the Status Quo of Teachers' Role Transformation in the Information Age. Computer Products and Circulation, 11, 150.

[2] Wei, R., Liu, J., Bai, X.W., Ma, X.Y., Liu, Y., Ma, L.H., Gan, Q.L., Kang, C.P. and Xu, G.X. (2020) Research Design of "5C Model of Core Literacy in the 21st Century". Journal of East China Normal University (Education Science Edition), 38, 20-28.

[3] Bu, X.M. (2020) Remolding the Role of Teachers Based on Learning Engineer. Modern Vocational Education, 39, 220-221.

[4] Lu, B.B. and Li, L. (2020) The Change of Teacher's Role from the Perspective of Deep Learning. Science, Education and Culture (Xunyuan), 9, 55-56.

[5] Wei, M. and He, Z.Y. (2020) Remolding the Role of Teachers by Artificial Intelligence from the Perspective of Technological Phenomenology. Research on Audio Visual Education, 41, 108-114.

[6] Ye, H. (2019) Teaching Reform from the Perspective of High Quality Development of Open University in the New Era. Journal of Distance Education, 37, 3-11. 